\title{
Structural integrity analysis and damage assessment of a long composite wind turbine blade under extreme loading
}

\author{
Himayat Ullah ${ }^{\mathrm{a}, *}$, Baseer Ullah ${ }^{\mathrm{a}}$, Vadim V. Silberschmidt ${ }^{\mathrm{b}}$ \\ ${ }^{\mathrm{a}}$ Centre of Excellence in Applied Sciences and Technologies (CESAT), Islamabad, Pakistan \\ ${ }^{\mathrm{b}}$ Wolfson School of Mechanical, Electrical and Manufacturing Engineering, Loughborough University, Leicestershire LE11 3TU, UK
}

A B S T R A C T

\begin{abstract}
The high demand of low cost wind energy needs to design large scale turbine blades with reduced weight which poses great challenges to their structural integrity while prone to extreme wind gusts. The loading can cause large-deflection bending and damage leading to significant drop in the load-bearing ability of long composite wind turbine (WT) blades. In this study, a comprehensive finite element (FE) modelling procedure is developed to simulate structural integrity and damage in composite blade using ANSYS software. The three-dimensional blade model is analyzed by carrying out geometrically nonlinear FE analysis to investigate the blade deformation and highly stressed regions leading to possible failure modes. The results show that the blade suction side is subjected to high compressive stress causing local skin buckling, which is further investigated using linear buckling analysis. Such local buckling drives interfacial debonding between skin and spar joined with a weak adhesive. Subsequently, the interfacial damage in the identified critical region is modelled by developing a damage submodel employing cohesive zone model (CZM) approach at the skin-spar interface. The analysis results indicate that buckling driven skin-spar debonding at adhesive interface is initial damage mode which can lead to progressive failure of the blade structure. Consequently, the ultimate load bearing capacity of WT blade is governed by a coupled buckling and debonding phenomenon even at load level below the ultimate design load. The simulation methodology adopted in this study can be employed to develop reliable and cost-effective computational tools for analyzing structural integrity and assessing damage in blade structure than expensive experimental testing.
\end{abstract}

\author{
Keywords: \\ Wind turbine \\ Composite blade \\ Structural analysis \\ Buckling \\ CZM \\ Debonding
}

\section{Introduction}

Generation of wind power, a source of low cost renewable energy, has been increasing over the past decade [1]. This high demand of wind energy at reduced cost is pushing the industry to design large scale wind turbines. However, increasing the blade size poses substantial design challenges in terms of strength, stiffness and weight of the blade. Hence, the turbine blade is considered as the most important and critical structural element of a WT system [2]. This essentially needs some efficient materials and reliable analysis methods to address the structural integrity challenges such as severe gusts during operation, which are experienced by the blades during service. The advanced composite materials have the potential to withstand efficiently the large-deflection bending caused by severe loading conditions. Due to their higher specific stiffness, specific strength, exceptional corrosion resistance and fatigue strength, the fiber-reinforced composite laminates and sandwich structures are widely employed for turbine blades nowadays [3].
However, the loading conditions and harsh service environment generate high localized stresses leading to complex damage modes due to heterogeneity, microstructure and anisotropy of composite laminates and sandwich panels. Typical damage modes observed in composite blades are matrix cracking, fiber fracture, delamination between adjacent plies and interface adhesive debonding between skin and spar flanges [1]. Among these the most critical is the inter-ply delamination and adhesive debonding, which can reduce the material's in-plane compressive strength and stiffness significantly. The major parts of a WT blade such as spar flanges, shear webs and shells are mostly joined through adhesives having lower through-the-thickness stiffness and strength [4]. Under extreme wind gusts, the blade is subjected to largedeflection bending causing discontinuities in the blade especially at adhesive joints between the aerodynamic shell and spar flanges. This results in geometric instability in the form of skin buckling and delaminaion between the skin and spar [5]. Such internal damage mechanisms that are barely visible can degrade the load-carrying ability of

\footnotetext{
* Corresponding author.

E-mail address: uhimayat@gmail.com (H. Ullah).
} 


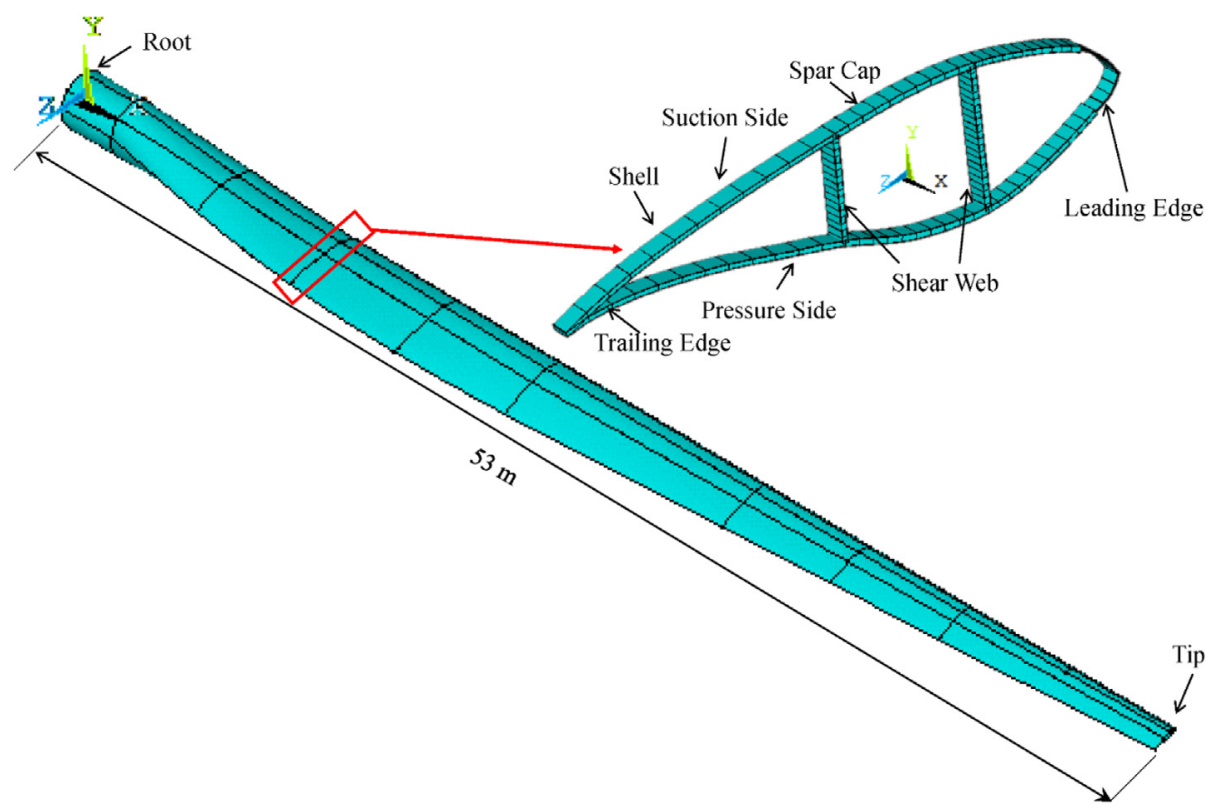

Fig. 1. Aerodynamic configuration and structural elements of blade.

the WT blades. These damage mechanisms cause progressive failure of the blade, thus governing the ultimate strength of the blade structure. The adhesive joint debonding coupled with shell buckling phenomenon was revealed in full scale testing of a composite blade which led to the structural collapse before reaching its limit design load [4-6]. Further, in flap-wise bending test of $52.3 \mathrm{~m}$ long composite blade among various damage modes, delamination of spar cap laminate was identified as the root cause for ultimate failure of the blade due to high local compressive stresses [7]. These experimental studies indicate that local debonding initiates at the adhesive interface of skin and spar cap on the compression side of blade due to geometric instability. Thus the local skin buckling acts to induce damage at the adhesive interface even at stress and strain levels below the material's design limits. Upon increasing the applied load, damage progression occurs along with redistribution of load on the debonded skin and spar cap. This phenomenon leads to high compressive stress state at the skin and spar exceeding the materials' limit, which subsequently cause catastrophic failure of the blade. Therefore, it is vital to look into the structural integrity of long blades in terms of strength, stability and damage modes for their safe design and performance.

Structural integrity of turbine blade is generally evaluated by experimental testing and numerical simulations. In experimental testing procedure, several tests of the full scale blade are performed in various directions and loading conditions for blades' qualification according to standards such as IEC-61400-1 and Germanischer-Lloyd (GL) regulations $[8,9]$. However, these tests are very costly and time consuming and not favorable especially in the design phase where several combinations of loading conditions are analyzed. Further, these tests measure the stresses and deformations of the blade without assessing the initiation and progression of the barely visible damage modes along with identification of their location in the structure. Contrarily, high fidelity simulations based on FE models are capable to analyze the blade structural performance as well as predict the location of damage along with its initiation and evolution under various loading conditions. Nowadays, computational models based on FE techniques are widely developed to predict the structural integrity and failure of WT blades. In these studies, certain composite blade models only considered damage initiation and evolution in the WT structures [10-12] while others only considered the global response of blades in terms of deformation and stress levels [13-16]. Additionally, although damage evolution was simulated in some blade models, they were often based on failure criteria such as Tsai-Wu or Tsai-Hill which did not account for any physical damage or the associated material stiffness reduction $[14,15]$. Such material's behavior must be considered in order to accurately predict the nonlinear response of materials employed in the analysis of blade structures. Therefore, development of an improved modelling approach is required to assess the blade local and global structural performance as well as onset and growth of damage in blade, which is the focus of this paper.

In this study, a comprehensive methodology based on FE analyses is presented to assess the blade structural integrity, stability and adhesive interface debonding. The blade geometric model is created in an open source tool numerical manufacturing and design (NuMAD) [17] and then imported to ANSYS as a geometry for further analysis. Under the extreme gust conditions, blades are subjected to largest aerodynamic loads, which are usually determined by using blade element momentum (BEM) theory and computational fluid dynamics (CFD) models $[13,18]$. As the CFD based methods are computationally expensive [19], thus the BEM theory is employed here to calculate the blade pressure profile. Structural integrity assessment of the developed blade in terms of criticality is the analysis under extreme loading to determine stress levels and blade tip deflections against the design criteria as specified by the standards $[8,9]$. The extreme loading nonlinear FE analysis identifies the location of high compressive stresses resulting in local skin buckling and damage. The critical load and extent of skin deformation is predicted with a linear buckling analysis. Subsequently, the buckling induced adhesive debonding in the identified critical region is modelled with cohesive zone model (CZM), capable of simulating initiation and propagation of damage simultaneously. In this work, modelling of adhesive interface debonding based on CZM is the latest approach for damage assessment under large-deflection bending.

\section{Blade structural design}

\subsection{Blade description}

The blade aerodynamic configuration constructed of sandwich structures and thick composite laminates is shown in Fig. 1. Here, the main parts of the blade are load bearing spar, shear webs and the suction and pressure aerodynamic shells (skins). The suction and pressure side skins are adhesively bonded to the spar cap and these skins are also bonded with each other at the leading and trailing edges 
of the blade. The spar caps are made of unidirectional (UD) composite laminates with fibers along the blade length in span-wise direction. Thickness and layup of the spar caps is selected such as to resist the bending moment caused by aerodynamic loads effectively. Shear webs towards the leading and trailing edges consisted of sandwich composites i.e. laminate/core/laminate structure to resist shear. Similarly, aerodynamic shells were made of sandwich laminate/core/laminate structure to bear torsion and shear loads and maintain aerodynamic profile of the blade. The spar caps along with shear webs and skin makes a box beam section, efficient for flexural and torsion load bearing. Here, the blade composite layups consist of thick laminates in the spar flange and leading edge, sandwich structure in the blade shells and shear webs. The $2.3 \mathrm{MW}$ wind turbine blade having $53 \mathrm{~m}$ length and $3.4 \mathrm{~m}$ maximum chord with NACA 63-XXX airfoil is considered for analysis. The blade transitioned from the root circular section to the airfoil over the span of $7.5 \mathrm{~m}$. Two shear webs, at $15 \%$ and $50 \%$ of the chord length are placed, and sturdy spar caps are used between them. The blade has a twist of about $15^{\circ}$ from root to tip. Geometric model and details of various parts of the blade are shown in Fig. 1.

\subsection{Material selection}

Various parts of the blade are made of thick laminates and sandwich panels. Thick laminates and face sheets of the sandwich panels are made of glass fiber reinforced plastic (GFRP). Three main types of GFRP composite layups such as unidirectional laminate $\left[0^{\circ}{ }_{2}\right.$, bi-axial $\left[ \pm 45^{\circ}\right]_{4}$ (Saertex) and tri-axial $\left[ \pm 45^{\circ}\right]_{2}\left[0^{\circ}\right]_{2}$ laminates are employed. Materials' properties and their usage to various parts of the blade are illustrated in Table 1. Elastic and strength properties of GFRP laminates as well as balsa wood and foam core are taken from [20-24]. The leading edge section is comprised of $4 \mathrm{~mm}$ thick unidirectional (UD) GFRP laminate sandwiched between two $3 \mathrm{~mm}$ thick triaxial fabric layers. The spar flanges consist of a $30 \mathrm{~mm}$ thick UD layer of GFRP aligned along the blade span sandwiched between two $3 \mathrm{~mm}$ thick triaxial fabric layers. Here, UD laminates are used to resist uniaxial tension and compression in the spar caps along the blade span when subjected to bending load. In the shear webs, $30 \mathrm{~mm}$ thick balsa wood is sandwiched between two $3 \mathrm{~mm}$ thick biaxial fabric layers. The rest of the shell and trailing edge are made of sandwich structure consisting of a $25 \mathrm{~mm}$ thick lightweight foam core and two $3 \mathrm{~mm}$ thick triaxial fabric skins. Both the triaxial and biaxial laminates are modeled as 3 plies with stacking order of $45^{\circ} /-45^{\circ} / 0^{\circ}$ and 2 plies with stacking order of $45^{\circ} / 45^{\circ}$, respectively. Shell structures are made of triaxial fabrics to resist both the bending and shear loads during service.

\section{Finite element structural analyses}

Virtual models based on FE method are capable of simulating the overall structural response as well as entire damage process from its initiation through evolution to complete composite structure failure. This analysis approach also reduces the number of experimental tests needed for design development, which can be termed as a virtual testing. During service, the slender blade structure consisting of several adhesively bonded parts is subjected to large-deflection bending under wind loads. Besides this geometric nonlinearity, the blade is also subjected to material as well as status change or contact nonlinearity. Softening and damage initiation of adhesive layers is a material nonlinearity and propagation of damage and debonding resulting in opening of interfaces is a contact nonlinearity. To simulate these nonlinearities, three types of FE analyses have been carried. The first one is a nonlinear structural analysis under large-deflection bending resulting in local skin buckling above the spar cap. To further elucidate and investigate this behavior, a linear buckling analysis has been carried out. The local skin buckling initiates debonding/delamination between the skin and spar cap, which is simulated through a damage submodel incorporating CZM.

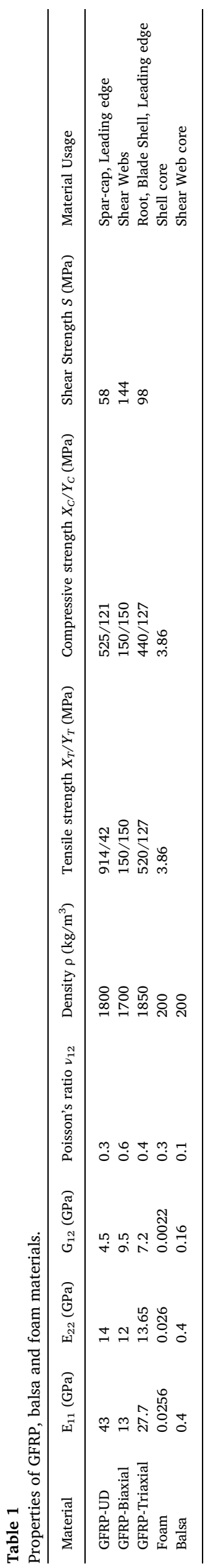




\subsection{Finite element model}

The blade 3D surface model is developed in NuMAD, which creates a model consisting of the blade geometric and material details. The code easily generates 3D model and effectively handles all blade information including airfoils, material properties and their geometrical characteristics. The 3D geometric model is imported to ANSYS Mechanical APDL for subsequent analyses. The blade is meshed with Shell 181 element type, which is based on the first order shear deformation theory, as layered shell element with 6 degrees of freedom at each node. The element can reproduce the behavior of layered composite structures by specifying the sequence of plies, thickness and orientation of each ply and the employed material. Orthotropic material models are defined for all the five materials listed in Table 1. These materials are assigned to different sections by using the shell layup command in the ANSYS preprocessor. The relative orientation is necessary to take into account the anisotropy of composite laminates. The materials' assignments to various blade sections resulted in $8,900 \mathrm{Kg}$ blade weight. A typical 2.0 MW blade weighs about 7,575 Kg as mentioned in [25]. Based on this reference, the weight of 2.3 MW blade should be around $8712 \mathrm{Kg}$ as a close estimate. The variation in the mass of modelled and reference blade is about $2.2 \%$, which proves the rationality of the modelling approach.

\subsection{Nonlinear structural analysis}

When subjected to bending loads, large deflections and rotations occur in the blade, which may cause warping and out-of-plane deformation in the blade geometry. This makes the blade response as geometrically nonlinear, which needs to be considered in the blade structural analysis. The numerical analysis is focused on the prediction of global and local deformations, stresses and identification of critical regions of the blade which are most susceptible to failure under severe loading. The blade is discretized with a mesh size of $0.1 \mathrm{~m}$ on each side of element to take into account both the accuracy and computational cost of the nonlinear analyses. The resulted FE model consists of 60,785 elements and 59,875 nodes. The FE model along with the applied boundary conditions is shown in Fig. 2. Here, the global $\mathrm{x}$-axis is aligned with blade span, y-axis along normal to chord and z-axis along the chord. The blade is fully constrained at the root to replicate its fixing to the rotor hub; and free at the tip acting as a cantilever beam. In Fig. 2, the symbols ' $U$ ' and 'ROT' represent nodal translations and rotations, respectively, which are fixed i.e. set to zero in all directions at the root. The symbol 'ACEL' represents the gravitational force applied as acceleration shown by red arrow at the root. The blade tip is modelled as a rigid region to restrict its out of plane deformation, with the nodes located at the tip constrained to a master node in the center represented by constraint equation (CE) in Fig. 2.

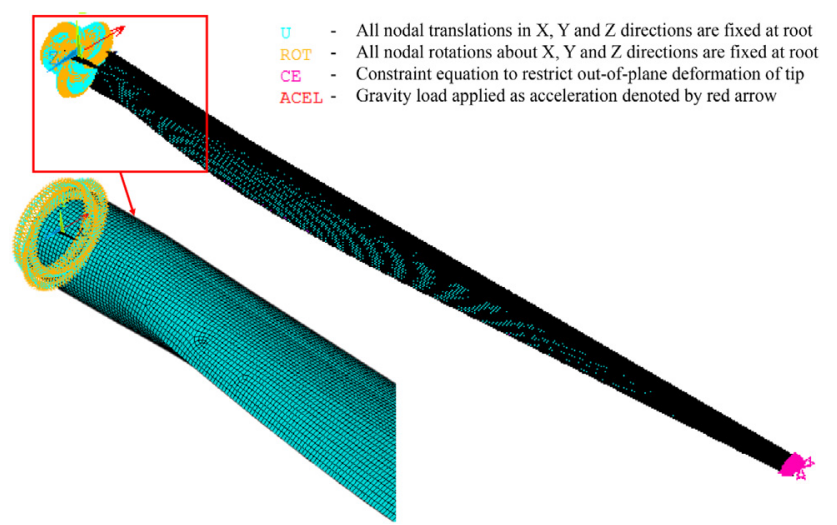

Fig. 2. FE meshed model along with applied boundary conditions.

\subsubsection{Loading}

Main types of loading on blade are aerodynamic, gravitational and centrifugal forces during normal operation and severe conditions [1]. Aerodynamic loads are the largest ones causing large-deflection bending of the blade especially under extreme gust condition. The aerodynamic lift, $\mathrm{F}_{\mathrm{L}}$, and drag, $\mathrm{F}_{\mathrm{D}}$, forces depend on various factors e.g. wind speed, $\mathrm{v}_{\mathrm{w}}$, local blade speed, $\mathrm{vb}$, blade span, airfoil section, and local angle of attack. Using BEM theory, the lift, $\mathrm{F}_{\mathrm{L}}$, and drag, $\mathrm{F}_{\mathrm{D}}$, forces on discrete segments along the blade length are given as,

$F_{L}=\frac{1}{L} \rho v_{\text {res }}^{2} C_{L} A$

$F_{D}=\frac{1}{2} \rho v_{\text {res }}^{2} C_{D} A$

where, $C_{L}$ and $C_{D}$ are lift and drag coefficients, respectively, which are based on the airfoil data. As $C_{D}$ is negligible up to $12^{\circ}$ angle of attack, thus only lift force with $C_{l}=1.2$ is determined. The $\rho=1.225 \mathrm{~kg} / \mathrm{m}^{3}$ is the air density at sea level, ' $A$ ' is the blade planform area and ' $V_{\text {res }}$ ' is the resultant relative velocity component. Further, the gravitational force which causes edgewise bending from leading to trailing edges during rotation is applied as acceleration body load to the entire structure through the gravitational constant $\mathrm{g}=9.81 \mathrm{~m} / \mathrm{s}^{2}$.

The extreme wind model of gust in 50 years according to design load case 6.2 specified by IEC-61400-1 standard [8] gives $59.5 \mathrm{~m} / \mathrm{s}$ wind speed for Class IIB WT. Using Eq. (1) for this condition, the total lift force calculated is $347 \mathrm{kN}$. This force is applied in the form of pressure on the blade pressure side causing large-deflection flap-wise bending. Here, the wind loads are applied as pressure distribution on various blade segments to alleviate stress concentration effects due to singular pointed loads. In this study, only aerodynamic and gravity loads are applied as the blade is in parked condition, without centrifugal loads. The gravity is applied from leading to trailing edge along the z-axis (chord) as shown in Fig. 2.

\subsubsection{Composite failure criterion}

Tsai-Wu failure criterion is widely used for composite materials due to its relatively better accuracy and simplicity. The criterion is given as under:

$F_{11} \sigma_{1}^{2}+2 F_{12} \sigma_{1} \sigma_{2}+F_{22} \sigma_{2}^{2}+F_{66} \sigma_{6}^{2}+F_{1} \sigma_{1}+F_{2} \sigma_{2}=1$

where the subscripts 1 and 2 represent the longitudinal and transverse directions of a lamina, respectively, and 6 denotes in-plane shear. The parameters $F_{11}, F_{22}, F_{12}, F_{66}, F_{1}, F_{2}$ in the above equation are related to the material's strengths as given below:

$$
\begin{aligned}
F_{1} & =\frac{1}{X_{t}}-\frac{1}{X_{c}}, F_{2}=\frac{1}{Y_{t}}-\frac{1}{Y_{c}}, F_{11}=\frac{1}{X_{t} X_{c}}, F_{12}=-0.5 \sqrt{F_{11} F_{22}}, F_{22} \\
& =\frac{1}{Y_{t} Y_{c}}, F_{66}=\frac{1}{S^{2}}
\end{aligned}
$$

where $X_{t}$ and $X_{c}$ are the tensile and compressive strengths along the fiber's direction, respectively, $Y_{t}$ and $Y_{c}$ are the tensile and compressive strengths along the transverse direction, respectively, and $S$ is the inplane shear strength of the lamina. Values of these strengths of GFRP composites taken from published data $[20,22,23]$ and given in Table 1.0 are used to determine Tsai-Wu failure indices of composites. The lamina failure is indicated when the Eq. (3) yields a value greater than 1.0.

\subsection{Buckling analysis}

Local or global buckling modes in the composite structure can trigger the skin-spar debonding in blade. In local buckling, deformation of mainly one sublaminate occurs on one side of the debonding e.g. skin buckling, whereas in global buckling, the whole delaminated composite structure is deformed e.g. skin-spar buckling. Both local and global 
buckling of the skin are one of the major causes of structural failure of WT blades [10]. The structural nonlinear analysis revealed local out-ofplane deformation and dimples at the skin above the spar caps. In order to further investigate this phenomenon, a linear buckling analysis of the blade structure is carried out using the linear buckling tool of ANSYS APDL. Here, the first eigenvalue and its corresponding eigenvector can be used to predict the buckling load and its associated mode shape of the blade. It is noteworthy that this is a theoretical buckling analysis as it is based on small deformation linear theory and does not take into account the geometric nonlinearity and manufacturing imperfections in the blade structure. Therefore, the theoretical load is usually higher than the actual buckling load. However, still it can be used as a preliminary analysis tool for assessment of structural instability of the blade.

\subsection{Skin-spar adhesive debonding}

During operation, the blade pressure side (PS) experiences tension whereas the suction side (SS) experiences compression under flap-wise bending. This compression can induce the geometric and adhesive material instability resulting in local buckling of thin skin. Consequently, this instability causes adhesive debonding i.e. delamination between the heavily loaded skin and spar [11]. The skin-spar debonding is modelled using CZM approach which is capable to capture the onset and propagation of damage $[26,27]$. The cohesive behavior assumes that damage of interface is characterized by progressive reduction of the material's stiffness driven by a damage process. Interface debonding initiates and propagates under the combined effect of normal and tangential stresses in mixed-mode debonding. The nominal quadratic stress criterion is used for onset of debonding in this study is given as

$\left(\frac{\sigma_{n}}{\sigma_{n 0}}\right)^{2}+\left(\frac{\sigma_{t}}{\sigma_{t 0}}\right)^{2}=1$

where $\sigma_{\mathrm{n}}$ and $\sigma_{t}$ are contact stresses in normal and tangential modes, respectively; and $\sigma_{\text {no }}$ and $\sigma_{\text {to }}$ are interface strengths in normal and tangential modes, respectively. For mixed-mode debonding, both normal and tangential contact stresses contribute to the total fracture energy and debonding is completed when the critical fracture energy values are reached for the components. Therefore, the propagation of debonding is simulated by combined energy criterion given as:

$\frac{G_{n}}{G_{n c}}+\frac{G_{t}}{G_{t c}}=1$

where $G_{n}$ and $G_{t}$ are the normal and tangential fracture energies at given interface tractions, respectively; $G_{\mathrm{nc}}$ and $G_{\mathrm{tc}}$ are the normal and tangential critical energy release rates, respectively. The debonding is defined by a damage parameter as:

$d_{m}=\left[\frac{\Delta_{m}-1}{\Delta_{m}}\right] \chi$

where the damage parameter $d_{m}=0$, for $\Delta_{m} \leq 1$ represents fully bonded interface, $0<d_{m}<1$ for $\Delta_{m}>1$ means the initiation of debonding, and $d_{m}=1$ denotes the fully debonded interface; $\Delta_{m}$ and $\chi$ are defined as:.

$\Delta_{m}=\sqrt{\left(\frac{u_{n}}{u_{n}^{c}}\right)^{2}+\left(\frac{u_{t}}{u_{t}^{c}}\right)^{2}}$

$\chi=\left[\frac{u_{n}^{c}}{u_{n}^{c}-u_{n}}\right]=\left[\frac{u_{t}^{c}}{u_{t}^{c}-u_{t}}\right]$

where $u_{n}$ and $u_{n}^{c}$ represents the contact gap at the maximum normal contact stress and at the completion of debonding, respectively; and $u_{t}$ and $u_{t}^{c}$ represents tangential slip distance at the maximum tangential contact stress and at the completion of debonding, respectively.
The cohesive zone between the skin and spar cap is modeled with surface to surface bonded contact using augmented Lagrange method. The normal and tangential stiffness of cohesive interface is defined by assigning normal and tangential penalty stiffness in the contact properties. The normal and tangential stiffness values of $3 e 14 \mathrm{~N} / \mathrm{m}^{3}$ and $1.5 \mathrm{e} 14 \mathrm{~N} / \mathrm{m}^{3}$, respectively, taken from [10] are assigned to the contact pair. The interface strengths and fracture energies are defined by assigning cohesive zone material model to the contact elements. The cohesive zone material normal $\left(\sigma_{n 0}\right)$ and tangential $\left(\sigma_{t 0}\right)$ strengths of 7.5 MPa and $15 \mathrm{MPa}$, and the normal $\left(G_{\mathrm{nc}}\right)$ and tangential $\left(G_{t c}\right)$ fracture energy values of $200 \mathrm{~J} / \mathrm{m}^{2}$ and $1000 \mathrm{~J} / \mathrm{m}^{2}$, respectively, are also taken from [10]. Here, the bilinear material model with tractions and critical fracture energies is defined by using the data table method of TB, CZM command with TBOPT $=$ CBDE. Command input for this material is given below:

\section{TB,CZM,1,2,CBDE}

TBDATA, $1, \sigma_{\mathrm{no}}, G_{\mathrm{nc}}, \sigma_{\mathrm{to}}, G_{\mathrm{tc}}, \eta, \beta$

where $\eta$ is artificial damping coefficient and $\beta$ is flag for tangential slip under compressive normal contact stress. Artificial damping is used in the CZM to stabilize the numerical solution as damage phenomenon is highly nonlinear causing convergence difficulties. It is activated by specifying the damping coefficient ' $\eta$ ' and should be smaller than the minimum time step size so that the maximum traction and maximum separation values are not exceeded in debonding calculations. Here, a value of $1 \mathrm{e}-8$ is used in the material properties. Since the skin is subjected to compression during debonding, therefore, tangential slip under normal contact stress is activated by setting parameter $\beta$ to 1 .

To simulate the adhesive debonding phenomenon, a submodel consisting of contact definition at the debonding region is developed. The term 'submodel' should not be confused with the modelling approach where a finely discretized local portion of a large model is separately analyzed by importing boundary conditions from a global analysis. The debonding region is a priori known from the global nonlinear structural analysis which is highlighted as red in Fig. 3. It starts at a span of $7.5 \mathrm{~m}$ from the blade root with $15.15 \mathrm{~m}$ length and $0.85 \mathrm{~m}$ width of cap; represented by contact pair elements CONTACT174 and 3D TARGE170. The debonding submodel contains 70,375 four node shell elements with a characteristic global length of $0.1 \mathrm{~m}$. A fine spatial discretization at the cohesive zone is required to predict the damage propagation properly [28]. However, such refinement may be restrictive due to higher computational power and time to analyze large structures. Turon et al. [27] demonstrated that artificially reducing the interfacial strength results in an increase of the cohesive zone, thus requiring coarse meshes in cohesive zone. Therefore, to employ an optimum mesh size in the interface, reduced interfacial strength values are used here instead of a typical interfacial strength of about $53 \mathrm{MPa}$ of glass fiber epoxy. In the debonding region, mesh is refined with a

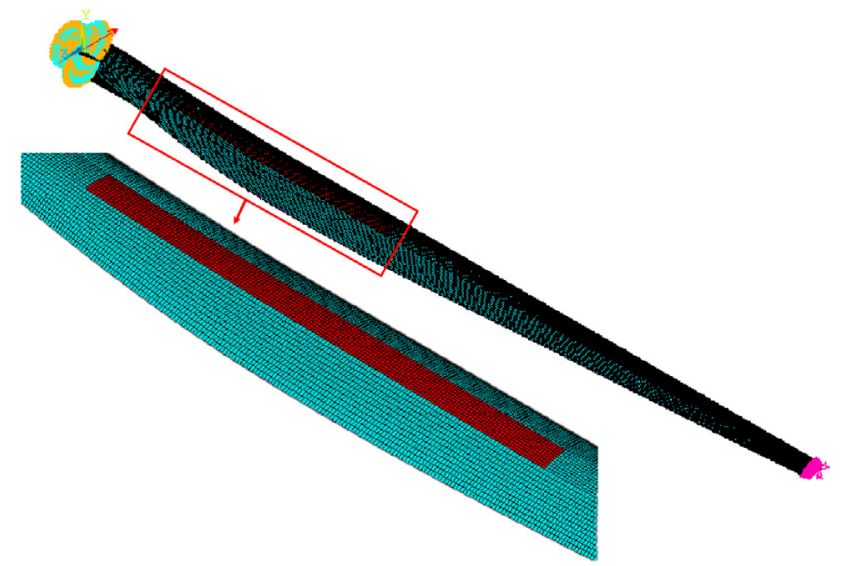

Fig. 3. Debonding submodel illustrating cohesive interface zone as red region. 
characteristic element length of $0.02 \mathrm{~m}$. Boundary conditions and loading is the same as used in the global nonlinear structural analysis.

\section{Results and discussion}

As specified by the standards IEC 61400-1 and Germanischer-Lloyd (GL), the blade should be capable to fulfill the design requirements such as the overall blade deformation limit i.e. the minimum distance between the blade tip and turbine tower, material stress and strain limits and critical buckling load. These requirements are investigated against the worst-case scenario of gust loads in structural nonlinear analysis as well as linear Eigen value analysis. Nonlinear structural analysis identified failure mode such as local buckling driven skin-spar debonding, which is also investigated in a separate damage analysis. Results of overall deflections, stresses and strains and buckling load are first presented followed by local results of adhesive debonding.

\subsection{FE model validation}

For validation of the FE model presented in Section 3.1, modal analysis is performed to compute the blade natural frequencies and mode shapes. The blade root is fully constrained with fixed boundary conditions. The first four blade mode shapes consisting of two flap-wise and two edgewise modes obtained from the vibration analysis are illustrated in Fig. 4. As can be seen, the blade natural frequency in the first flap-wise bending mode is $0.403 \mathrm{~Hz}$, which is within the range of $0.18-0.41 \mathrm{~Hz}$ for a similar blade reported in [29]. This mode also shows that the prominent deformation mode of the blade is flap-wise bending. Similarly, the natural frequency in the first edgewise mode is $0.605 \mathrm{~Hz}$ which is within the range of $0.54-1.23 \mathrm{~Hz}$ as specified in [29]. This validates the present methodology of FE modelling as well as assignment of the materials to various structural elements of the blade.

\subsection{Overall blade deformation}

In case of extreme wind condition, it is necessary to predict overall structural deflection of the blade to be within safe clearance limits. The overall deflection of the blade is shown in Fig. 5. The flap-wise tip deflection caused by aerodynamic bending is $9.66 \mathrm{~m}$, whereas the edgewise bending deformation caused by the gravity and torsion due to

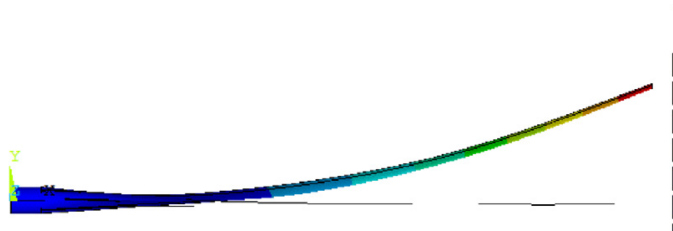

(a)

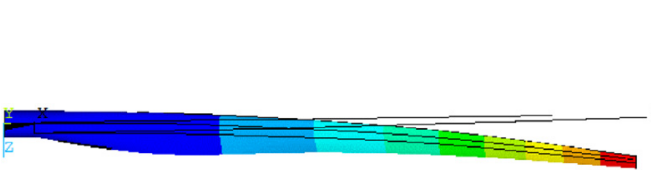

(b)
Fig. 5. Deflection (m) of blade under extreme aerodynamic and gravity loads: (a) flap-wise bending; (b) edge-wise bending.

twist in the blade geometry is $3.79 \mathrm{~m}$. This depicts the bend-twist coupling due to combined aerodynamic and gravity loads as well as twist in the blade geometry and anisotropic nature of composite materials. Here, when subjected to aerodynamic loads, the blade twists during bending, which changes the angle of attack, thus, directly mitigating the incident wind loads and increasing the blade life. This coupling can also be enhanced by orienting UD plies of spar cap at angles of $15-30^{\circ}$ with respect to the span axis [30]. Zuo et al. [1] reported the blade tip deflection of $9.65 \mathrm{~m}$ for $33.25 \mathrm{~m}$ long blade which is $29.0 \%$ of the blade length. Similarly, Yang et al. [4] reported this as $22.5 \%$ in a failure test of a $40 \mathrm{~m}$ long blade under extreme loading. Hence, the flap-wise tip deflection from the nonlinear analysis is $18.2 \%$, which is close to the cited values. The tip deflection can be controlled by increasing the blade stiffness employing various feasible options such as replacing glass fiber composites with carbon fiber composites, tailoring the layup sequence or adding more unidirectional plies in the spar cap.

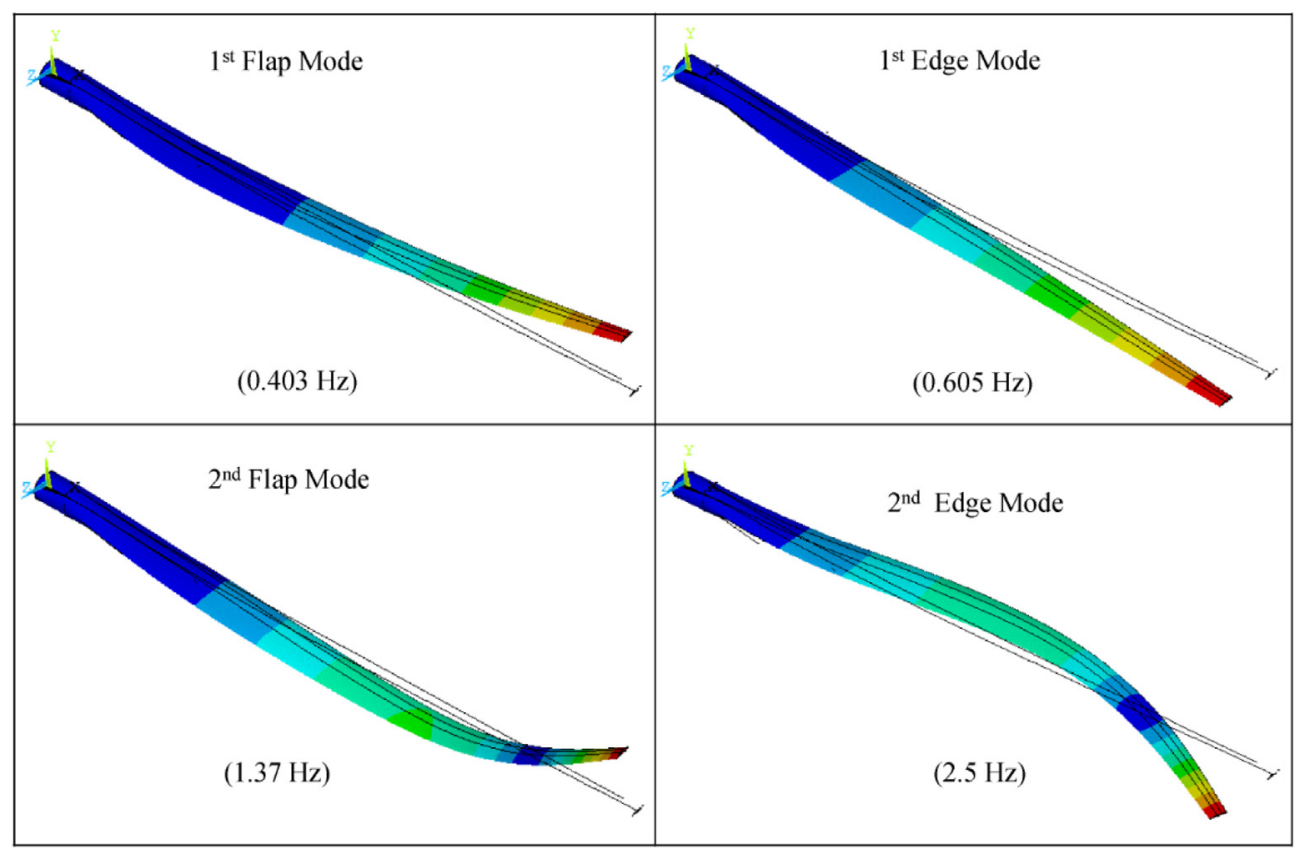

Fig. 4. Modes shapes of the blade in flap-wise and edge-wise directions. 


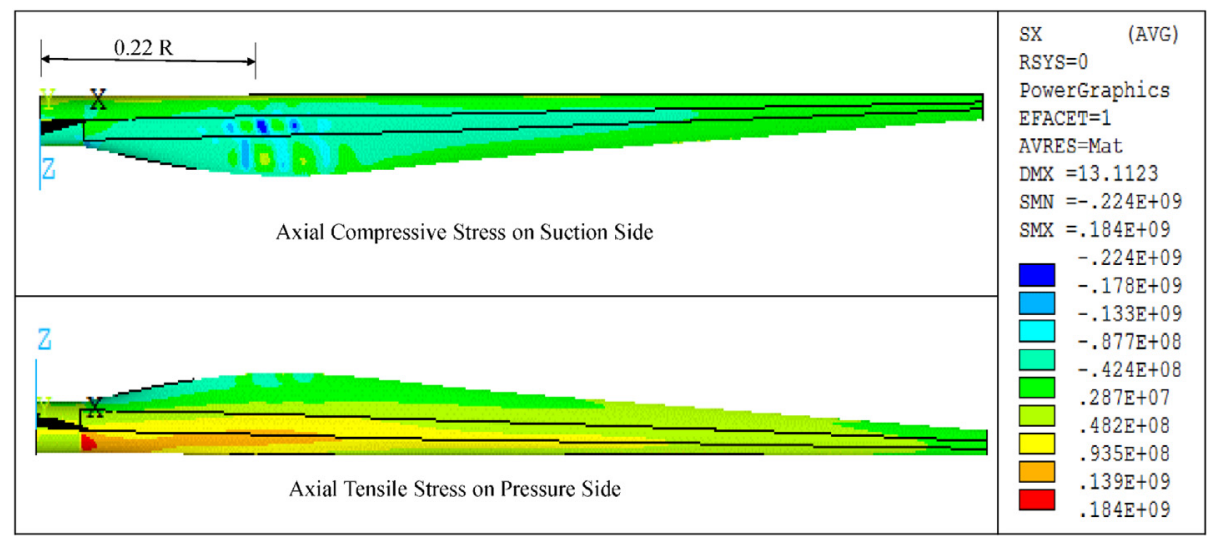

Fig. 6. Axial compressive and tensile stress (Pa) on the fabric shell.

\subsection{Stress and strain analysis}

Contour plots of axial stress of the blade shell at ultimate load are illustrated in Fig. 6. The maximum axial stress of $224 \mathrm{MPa}$ occurred on the suction side of the shell which is subjected to compression during flap-wise bending. The high stress region of the shell and spar is located between the shear webs at R0.22 i.e. $22.0 \%$ of blade radius from the root. The high compressive stress initiates local buckling which subsequently causes local adhesive debonding between the skin fabric and spar. The pressure side is under tension with $184 \mathrm{MPa}$ maximum axial stress at transition region between the circular root and the airfoil shape of the blade. Similar axial stress distribution along the blade span was also observed by Zuo et al [1].

As the spar caps are made of stiffer UD laminates, thus the max compressive stress of $403 \mathrm{MPa}$ occurred on the top spar cap and $269 \mathrm{MPa}$ tensile stress occurred on the bottom spar cap as shown in Fig. 7. The results indicate that the spar caps are the main load-carrying structure during large-deflection bending. Response of the skin fabric under compression above the spar cap is illustrated in Fig. 8 in terms of Tsai-Wu failure indices for each layer of triaxial fabric with sacking sequence of $45^{\circ} /-45^{\circ} / 0^{\circ}$. As the first ply is away from the neutral axis of the blade, thus it is subjected to higher compressive stress, and fails first with higher failure index of 2.26 in $45^{\circ}$ direction. Subsequently, the 2nd ply is failed with failure index of 1.9 in $-45^{\circ}$ direction. The third ply is a UD which shows the failure index of 1.2 in $0^{\circ}$ direction. The results clearly indicate that the skin fabric is locally failed under compression during bending load. These results are further corroborated by the longitudinal strain response on the spar cap skin along the blade length as shown in Fig. 9.

Longitudinal strain on the SS as well as the PS skin shell along the middle axes of the spar caps against the applied bending load is illustrated in Fig. 9a and b, respectively. As shown, the strain levels

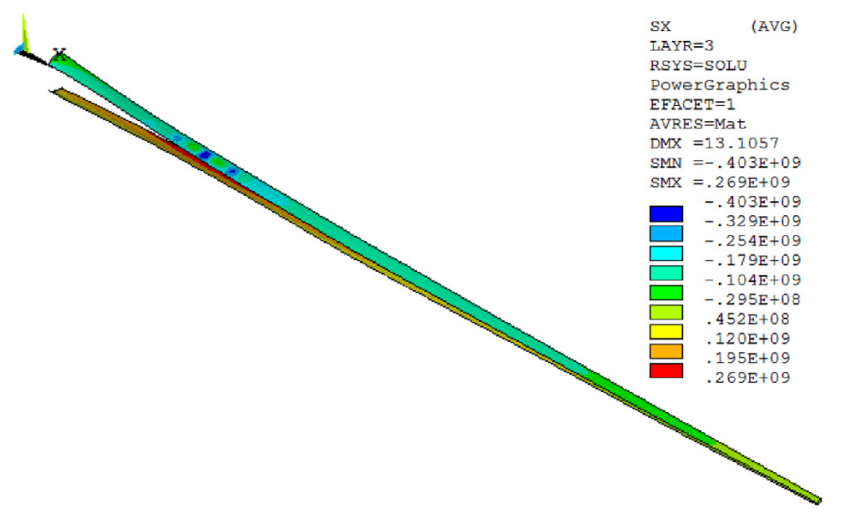

Fig. 7. Axial compressive and tensile stress (Pa) in the UDs of spar caps.

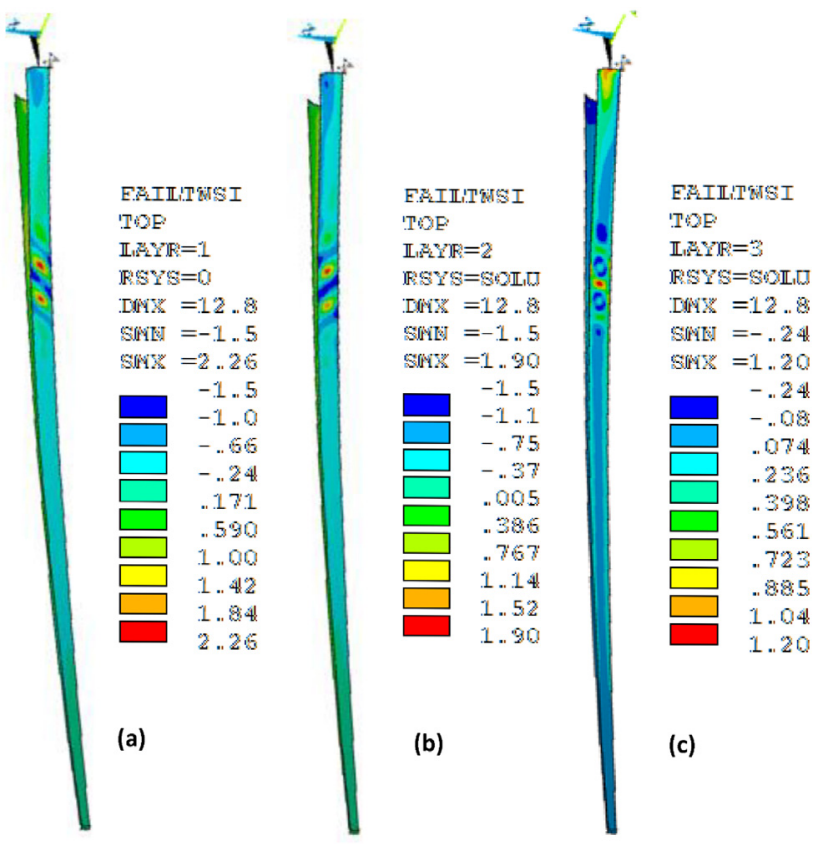

Fig. 8. Tsai-Wu failure indices of triaxial fabric skin under compression: (a) 1st ply $\left(45^{\circ}\right)$; (b) 2nd ply $\left(-45^{\circ}\right)$; (c) 3rd ply $\left(0^{\circ}\right)$.

increases with applied load on both the PS and SS shell in the blade region of R0.2-R0.3. As the applied load reaches $80 \%$ of the ultimate, a discontinuity is initiated in the strain response on the SS shell showing nonlinear bending response of the blade. The discontinuity grows as the applied load increases till the ultimate load and a strain reversal is observed at the location $\mathrm{R} 0.22$. This strain reversal accompanied with the highest compressive strain level of $6000 \mu \mathrm{m} / \mathrm{m}$ indicates local skin buckling. Subsequently, this deformation causes progressive debonding of the interface between the skin and spar cap due to local high stress concentration as observed in Fig. 6. Consequently, the blade collapse is caused initially by the compressive failure of skin shell at suction side. Similar failure behavior was also observed in experimental testing of the blade in [5], where the highest longitudinal compressive strain and local buckling near the region of R0.192 at SS caused sudden collapse of the blade. On the pressure side, the strain increases smoothly with increasing applied load, showing no local fiber failure as the strain level is still below the ultimate tensile strain of triaxial fabric. Here, the max tensile strain of $5000 \mu \mathrm{m} / \mathrm{m}$ occurs at R 0.25 of the blade.

The axial stress and Tsai-Wu failure indices in the biaxial fabric of both the leading edge (LE) and trailing edge (TE) shear webs under large-deflection bending are shown in Fig. 10. Both the shear webs 

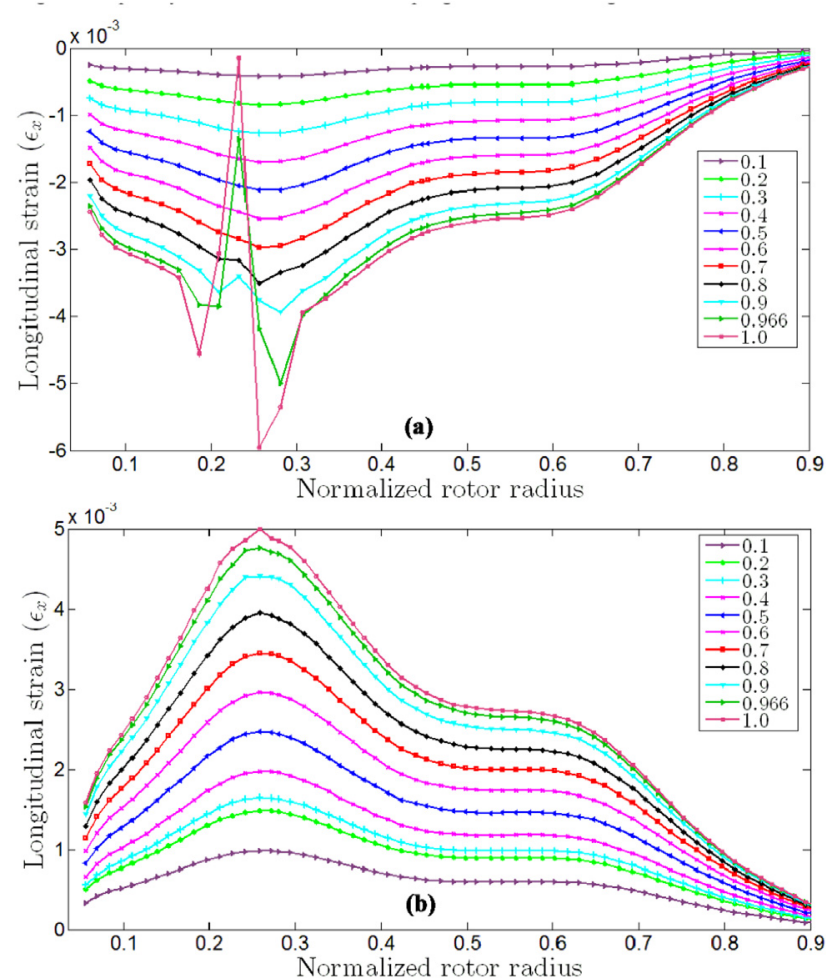

Fig. 9. Longitudinal strain as function of the normalized rotor radius along middle axes of spar caps at (a) Suction Side, (b) Pressure Side, w.r.t the ultimate loading.

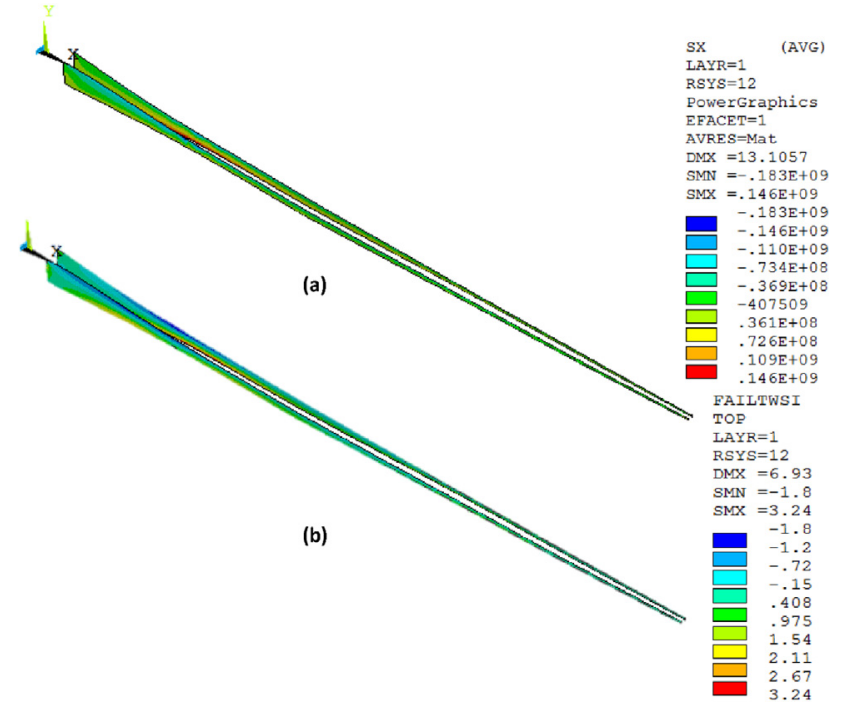

Fig. 10. Contour plots of (a) axial stress (Pa) and (b) Tsai-Wu failure indices in biaxial fabrics of shear webs.

experience compression and tension with $183 \mathrm{MPa}$ and $146 \mathrm{MPa}$ stress on the SS and PS, respectively. As the height of LE shear web is more than that of TE shear web, thus the former is subjected to higher stress level. Here, the compressive stress exceeds the compressive strength of biaxial fabric of $150 \mathrm{MPa}$. Thus the fabric of shear web is not safe as illustrated by the Tsai-Wu failure indices in Fig. 10b. Here, the LE shear web shows prominent tensile fabric failure on the PS, whereas both the shear webs show compressive failure on the SS. This indicates that number of biaxial plies should be increased to avoid bending dominated failure in the webs. Distribution of shear strain along the blade radius at middle axes of the shear webs is also presented in Fig. 11. Here, the TE

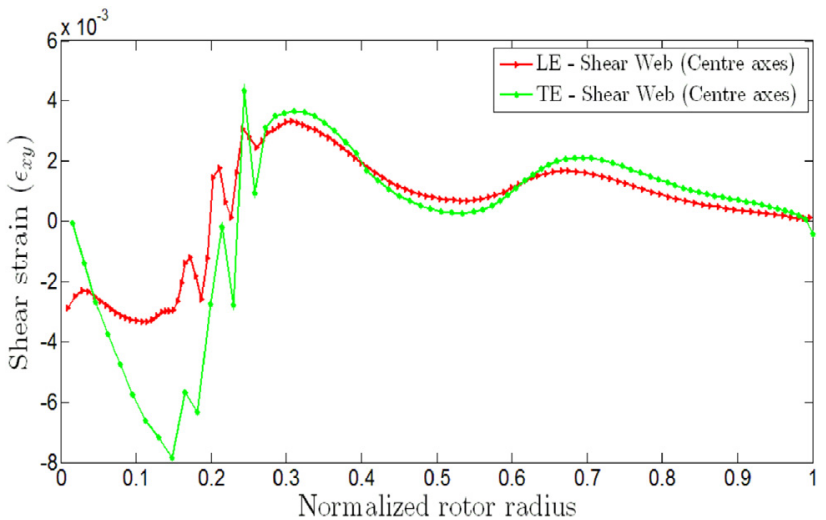

Fig. 11. Shear strain as function of the normalized rotor radius along middle axes of LE and TE shear webs at ultimate loading.

shear web is experiencing higher compressive strain in the R0.1- R 0.2 due to its lower height, whereas the LE shear web is under higher tensile strain in $\mathrm{R} 0.2-\mathrm{R} 0.3$ region. This also indicates that both the shear webs should be thickened to avoid the shear failure.

\subsection{Local deformation and buckling}

As illustrated in Figs. 6 and 9, the region of compressive damage is located in the R0.2 - R0.3 zone on the SS of the blade. To investigate this compressive behavior, local out-of-plane deformation is measured on the SS shell above the spar cap at various locations as shown in Fig. 12. The shell deformation increases linearly with applied load at regions R0.16, R0.20 and R0.25. As the applied load reaches $80 \%$ of the ultimate load, a bifurcation is observed in the shell at region R0.22. Now as the load increases, the deformation of the shell decreases. This shows the incipient local buckling of the SS shell. This behavior is more elaborated in the load vs strain response at R0.22 region as shown in Fig. 13. Here again the compressive strain increases with the applied load exhibiting linear behavior till $65 \%$ of the ultimate load and then nonlinear till $80 \%$ of the ultimate load. At this load, the compressive strain is reduced, showing a local bifurcation. Now the shell finds a new stable equilibrium condition at $85 \%$ load, and carries compression load but with reduction in structure's stiffness. At $90 \%$ load, snap-through collapse of the shell occurs as the strain sign is changed from compression to tension. This snap-through is characterized with loss of

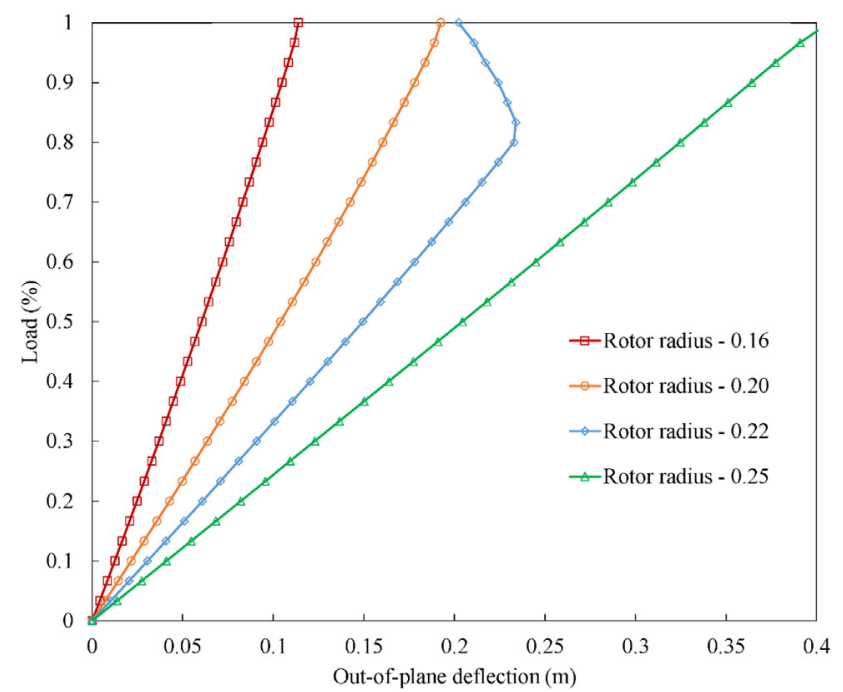

Fig. 12. Load vs local out-of-plane deflection curves at the middle of spar flange skin on Suction Side. 


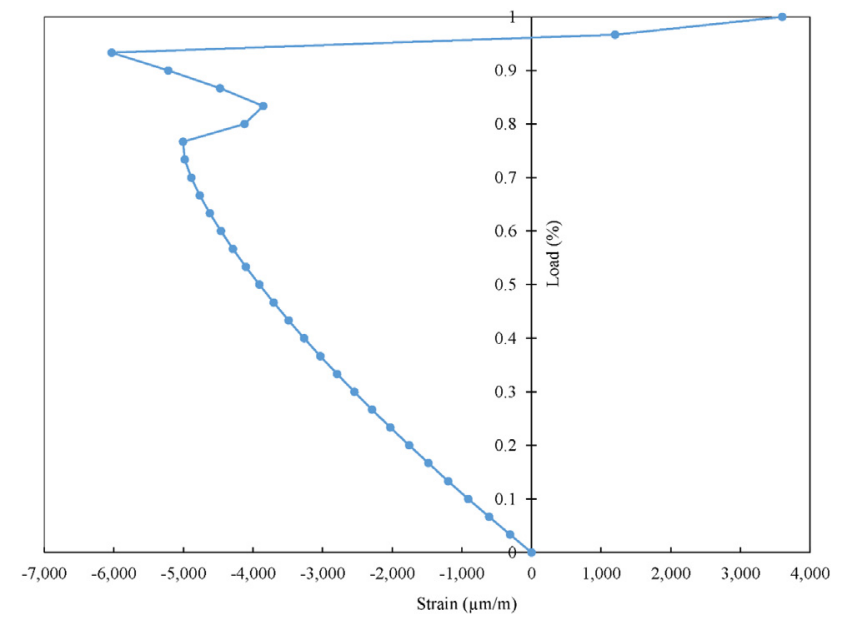

Fig. 13. Load vs strain response of skin on Suction Side at location R0.22 illustrating local buckling.

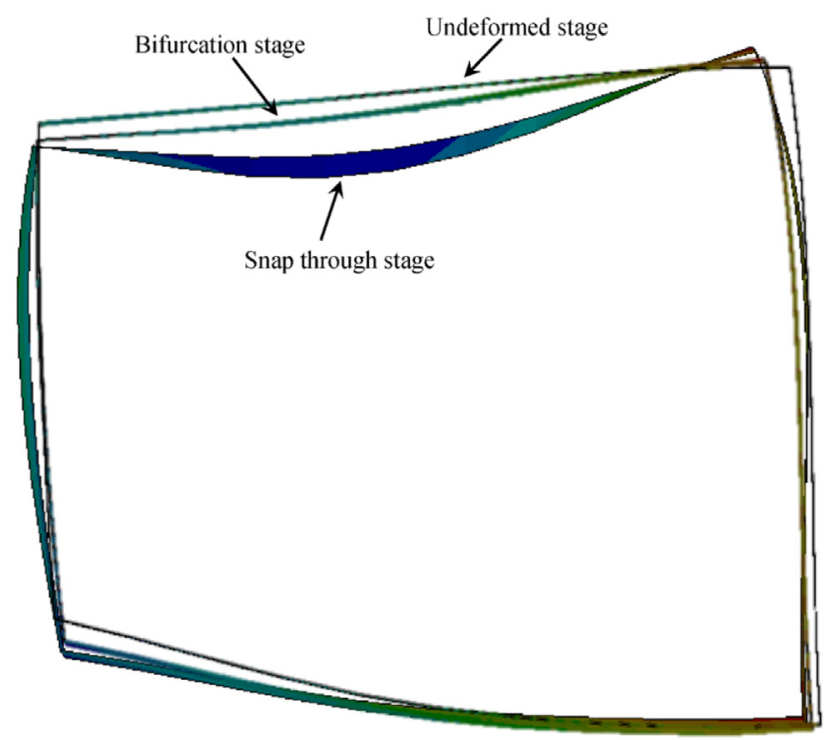

Fig. 14. Deformation of cross section of the main spar at various loading conditions.

structure's load-carrying capacity after the limit is reached. Simulation provided a better insight into the local snap-through behavior of shell which cannot be directly assessed in experimental testing of blade structure. The local deformation of the spar box section consisting of flanges and webs is shown in Fig. 14. At bifurcation point, the spar top flange is compressed whereas at snap-through, a large localized nonlinear bending deformation is occurred. This deformation reduces the load carrying capacity, which will result in collapse of the main spar if the adjacent structure is unable to withstand this extra load. As observed, the top spar flange is largely deformed and the rest of the structure is still capable to bear the applied load. The observed deformation behavior of ovalization and flattening of blade cross section under bending load is also termed as Brazier Effect [4]. This nonlinear deformation reduces the cross-sectional bending stiffness and thus the structure's ability to withstand bending loads. However, as argued in [11], contribution of Brazier Effect to the overall strain response in the spar cap is very limited due to small local out-of-plane deflection compared to the size of cross section and large circumferential stiffness of the main-spar in the blade structure. The blade ultimate load carrying capacity is specified by geometric and material induced instabilities i.e. local buckling and interface damage between skin and

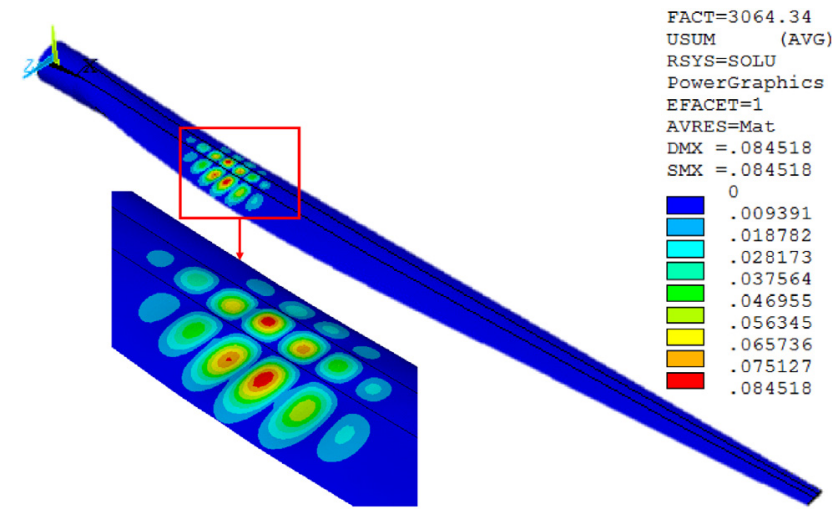

Fig. 15. Local Eigen value buckling of skin shell on Suction Side.

spar. Based on the above analysis, it is observed that the exact damage location is near the region of R0.22 on SS of the blade.

In order to further investigate the local deformation of skin shell, an Eigen value buckling analysis is performed. The first critical buckling mode is shown in Fig. 15. The dimples on the SS of shell are located around R0.22 region. Here, apart from the skin on the spar cap, skin towards the trailing edge is also locally buckled, indicating lower stiffness of the sandwich shell. The critical buckling pressure is 3064.0 Pascal which is equivalent to $358.0 \mathrm{kN}$ normal load. However, in nonlinear large-deflection analysis, this load is $277.6 \mathrm{kN}$ at $80 \%$ of ultimate load. Hence, there is a discrepancy of about $29.3 \%$ in the linear and nonlinear buckling load predictions. This mismatch is due to the fact that linear buckling analysis is based on small deflection theory predicting higher critical load than nonlinear large-deflection buckling analysis. Further, geometric imperfections such as variation in thickness and material imperfections also reduce the theoretical buckling load as investigated in [31]. However, the linear Eigen value buckling analysis predicted the mode shape and location of buckling. This analysis corroborated that the compressive damage of skin is caused by local buckling. Actually, the skin local buckling has been an area of concern for the wind energy industry due to the costs involved in repair and maintenance of the blades [16]. As the skin is made of sandwich structure, buckling strength of the skin can be enhanced by increasing the core thickness in sandwich panels. Increasing the core thickness, increases the bending moment of inertia, which increases the stiffness of the sandwich structure and thus prevent buckling.

\subsection{Skin-spar debonding}

Under flap-wise bending, the blade SS experiences local buckling which induces debonding between the skin and spar cap. As shown in Fig. 16, during local buckling of the skin, high stresses in the skin laminate can be observed. In Fig. 16a, at $80 \%$ loading, a single buckling mode in a sine wave form is shown, which moves to three modes at $90 \%$ load, representing the local skin debonding and opening, as illustrated in Fig. 16b. At 100\% load, five buckling modes are generated with max longitudinal compressive and tensile stresses of $529 \mathrm{MPa}$ and $191 \mathrm{MPa}$, respectively (Fig. 16c). It can be observed that the skin opening buckling mode causes stress concentration and that the compressive stress around the initial debond exceeds the compressive strength of $440 \mathrm{MPa}$ of triaxial fabric, leading towards the local skin failure. It is clearly illustrated that stress is redistributed on adhesive interface as the applied load increases showing debonding progression. The stress redistribution offers actual stress state to predict failure which results in skin structural instability.

The behavior of skin local buckling and the interface damage growth along with applied load is illustrated in Fig. 17. At a load level of approximately $80 \%$, a decrease in the out-of-plane deflection can be observed representing the skin local buckling. Simultaneously, the 


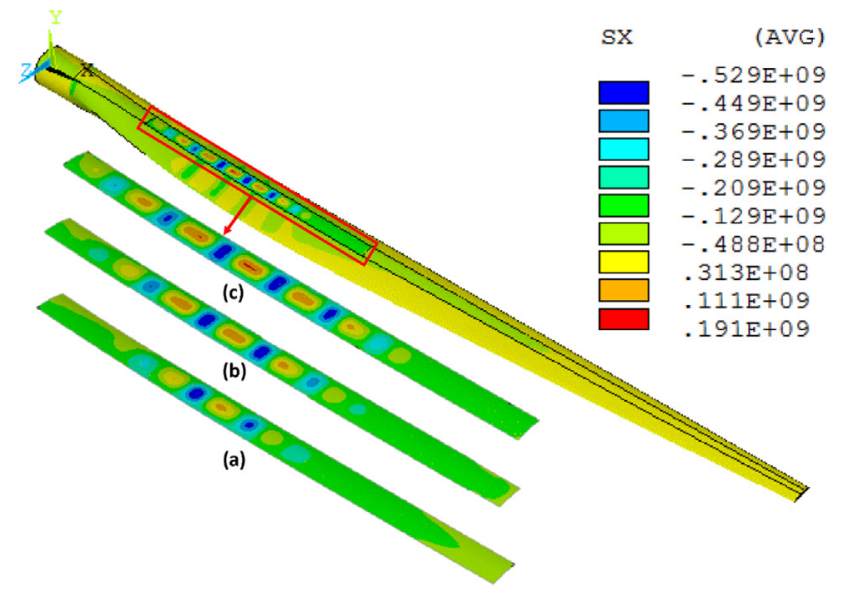

Fig. 16. Axial stress (Pa) contours showing local skin buckling modes along the blade at (a) $80 \%$, (b) $90 \%$ and (c) $100 \%$ of ultimate load.

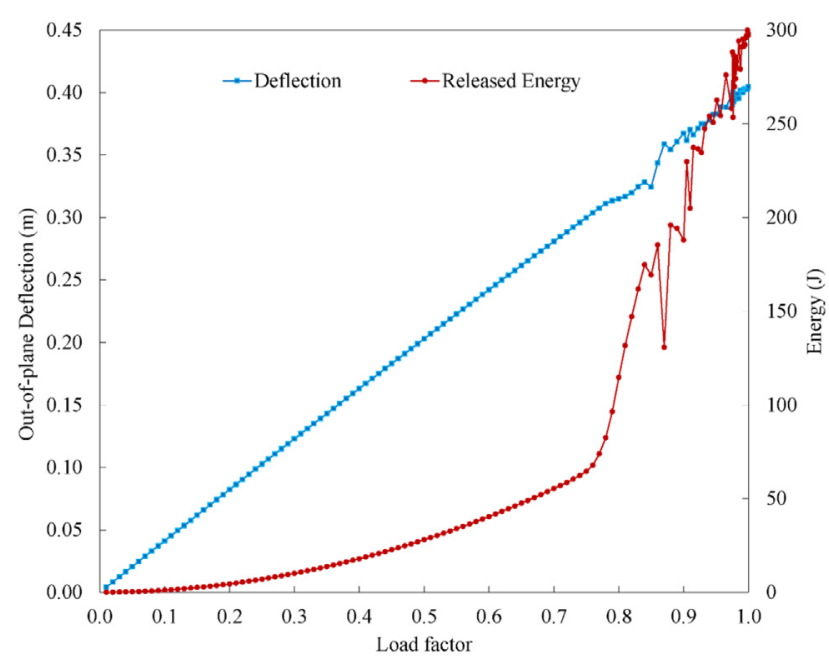

Fig. 17. Out-of-plane deflection and the released energy of the R0.22 location as a function of the applied load.

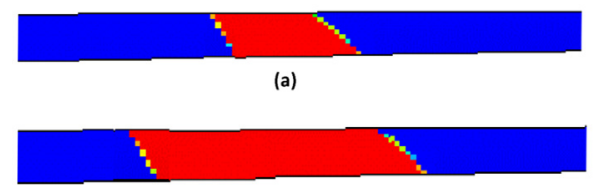

(b)

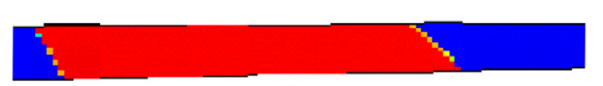

(c)

Fig. 18. Progressive debonding growth of the cohesive elements in the skin buckling region at (a) $80 \%$, (b) $90 \%$ and (c) $100 \%$ of ultimate load.

released energy level is increased, which shows that the debonding growth has started. The energy release is increased suddenly with little load application which characterizes an unstable damage growth after $80 \%$ load. As the applied load reaches $90 \%$, a small kink in the deflection can be observed. This kink can be attributed to change in the buckling mode shape as can be seen in Fig. 16b. The increase in the energy release shows damage propagation when it exceeds the critical energy level of the interface adhesive. The ultimate load is associated with five buckling modes as shown in Fig. 16c. The skin-spar damage propagation at the buckling region on the blade SS at various load levels is also shown in Fig. 18. The debond is illustrated in terms of damage parameter, with a value of 1.0 showing fully damaged and 0 fully intact interface. The damage progression originated from the locally buckled area at R0.22 and grew in a rectangular shape which is indicated by the damage state of the cohesive elements. The skin debonding length is about $2.2 \mathrm{~m}$ at $80 \%$ load at the compressive region on spar cap as shown in Fig. 18a. With increasing load level to $90 \%$, where the shell snap-through occurred, the length of debond region increases largely to $5.4 \mathrm{~m}$ (Fig. 18b). At 100\% load level, the extent of the debond grows to $8.8 \mathrm{~m}$ as shown in Fig. 18c. This extensive debonding development completely alters the load distribution in the spar cap. It can be observed that the damage growth is more towards the root due to highly localized stress region than the tip. It is noteworthy that the numerically predicted progressive interface debonding corresponds well with similar available findings of the full-scale testing of blade under bending loads as presented in [5]. The skin-spar debonding from the adhesive joints is an initial damage mechanism which can lead to ultimate blade failure under repeated load conditions. The CZM based modelling approach helped to predict initiation and growth of debonding process at various stages of loading along with identification of the location and size of damage, which is also helpful for the repair of blade.

\section{Conclusions}

In this paper, structural integrity and damage assessment of a long WT blade under extreme loading condition has been studied. Here, a comprehensive methodology of structural analysis of WT composite blade by combining the modeling and analysis tools i.e. NuMAD and ANSYS has been presented. The blade was first analyzed against extreme loading conditions where aerodynamic lift forces caused largedeflection flap-wise bending whereas the gravity load caused edgewise bending from leading towards trailing edge. Results demonstrated that the tip deflection is $18.2 \%$ of the blade length comparable to that of other similar systems. It was observed that suction side of the blade at $\mathrm{R}$ 0.22 region is exposed to compressive stress concentration inducing local skin buckling. The shear webs also experience higher stresses which can be reduced by increasing the number of biaxial plies in them. The local buckling in skin is further investigated through linear buckling analysis showing local skin buckles at the same location observed in the nonlinear large-deflection analysis. The predicted nonlinear critical buckling load is $29.3 \%$ lesser than the linear one, as the former is based on large deformation nonlinear theory. The high compressive stress on the blade suction side is mainly responsible for debonding between the spar cap and shell as these are joined through weak adhesive.

The skin-spar debonding was modelled through a sub-modelling approach where a subset of skin elements was connected to spar elements via contact elements at the critical region identified through nonlinear analysis. The initiation and growth of interface debonding was modelled by employing CZM approach. It was observed that damage initiated in the stress concentration region at R0.22 at adhesive interface prior to reaching the ultimate load. Debonding propagated along adhesive interface with increasing load, leading to redistribution of stress and local buckling modes. It is concluded that skin-spar debonding from adhesive interface is initial damage mechanism which can lead to earlier failure of blade before reaching ultimate design load. Consequently, the ultimate load bearing capacity of a WT blade is governed by a coupled buckling and debonding phenomenon, leading to its progressive collapse. Therefore, it is necessary to predict the loading condition and identify possible debonding region in the blade design process, which is possible by employing high fidelity numerical models. The CZM modelling technique was more comprehensive and provided better insight of the debonding process and local skin buckling behavior. Proposed damage mechanics based modelling approach for interfacial debonding in the structural elements of WT blade has potential to optimize the blade design and reduce the experimental test requirement in the design process and guide in repairing a damaged 
blade. The simulation methodology presented here will be useful for assessing the structural integrity and damage behavior for the design of safe and damage tolerant large-scale blade structures.

\section{Declaration of Competing Interest}

The authors declare that they have no known competing financial interests or personal relationships that could have appeared to influence the work reported in this paper.

\section{References}

[1] Zuo Y, Montesano J, Singh CV. Assessing progressive failure in long wind turbine blades under quasi-static and cyclic loads. Renewable Energy 2018;119:754-66.

[2] Brøndsted P, Lilholt H, Lystrup A. Composite materials for wind power turbine blades. Annual Review Material Res 2005;35:505-38.

[3] Verma AS, et al. Comparison of numerical modelling techniques for impact investigation on a wind turbine blade. Compos Struct 2019;209:856-78.

[4] Yang J, et al. Structural investigation of composite wind turbine blade considering structural collapse in full-scale static tests. Compos Struct 2013;97:15-29.

[5] Overgaard LC, Lund E, Thomsen OT. Structural collapse of a wind turbine blade, Part A: Static test and equivalent single layered models. Compos A Appl Sci Manuf 2010;41(2):257-70.

[6] Sørensen, B.F., et al., Improved design of large wind turbine blades of fibre composites (Phase 2)-Summary Report, 2005.

[7] Chen., X., et al. Preliminary failure investigation of a $52.3 \mathrm{~m}$ glass/epoxy composite wind turbine blade. Eng Fail Anal 2014;44:345-50.

[8] International Electrotechnical Commission (IEC) Design Standard, IEC 61400-1 Ed. 3: Wind turbines - Part 1: Design requirements.

[9] Germanischer-Lloyd (GL) Design Standard, Guideline for the Certification of Wind Turbines Edition. 2010.

[10] Haselbach PU, Bitsche RD, Branner K. The effect of delaminations on local buckling in wind turbine blades. Renewable Fneroy 2016:85:295-305.

[11] Overgaard LC, Lund E. Structural collapse of a wind turbine blade. Part B: Progressive interlaminar failure models. Compos A Appl Sci Manuf 2010;41(2):271-83.

[12] Ji YM, K.S.H.. Fracture mechanics approach for failure of adhesive joints in wind turbine blades. Renewable Energy 2014;65:23-8.

[13] Fernandez G, Usabiaga H, Vandepitte D. An efficient procedure for the calculation of the stress distribution in a wind turbine blade under aerodynamic loads. J Wind Eng Ind Aerodyn 2018;172:42-54.
[14] Junjie Ye CC. Heng Cai, Xiaonan Hou, Baoquan Shi, Shaohua Tian, Xuefeng Chen, Jianqiao Ye, A multi-scale model for studying failure mechanisms of composite wind turbine blades. Compos Struct 2019;212:220-9.

[15] Raman V, et al. Numerical simulation analysis as a tool to identify areas of weakness in a turbine wind-blade and solutions for their reinforcement. Compos B Eng 2016;103:23-39.

[16] Júnior CJF, et al. Modeling wind turbine blades by geometrically-exact beam and shell elements: A comparative approach. Eng Struct 2019;180:357-78.

[17] Berg JBR. Numerical manufacturing and design tool (NuMAD V2. 0) for wind turbine blades: User's guide, in Technical Report No. SAND2012-7282012: Sandia National Laboratories, Albuquerque, NM.

[18] Hansen MOL, Sørensen JN, Voutsinas S, Sørensen N, Madsen HA. State of the art in wind turbine aerodynamic and aeroelasticity. Prog Aerosp Sci 2006;42:285-330.

[19] Bazilevs Y, et al. 3D simulation of wind turbine rotors at full scale. Part II: Fluid-structure interaction modeling with composite blades. Int J Numer Meth Fluids 2011;65(1-3):236-53.

[20] Leong M, et al. Investigation of failure mechanisms in GFRP sandwich structures with face sheet wrinkle defects used for wind turbine blades. Compos Struct 2012;94(2):768-78

[21] Chou J-S, et al. Failure analysis of wind turbine blade under critical wind loads. Eng Fail Anal 2013;27:99-118.

[22] Griffith DT, Resor BR, Ashwill TD. Challenges and opportunities in large offshore rotor development: Sandia 100-meter blade research. AWEA WINDPOWER 2012 Conference and Exhibition. 2012.

[23] Haselbach PU. An advanced structural trailing edge modelling method for wind turbine blades. Compos Struct 2017;180:521-30.

[24] Linul E, Marsavina L. Mechanical Characterization of Rigid PUR Foams Used for Wind Turbine Blades Construction, Chapter: 10, in Recent Advances in Composite Materials for Wind Turbines Blades, B. Attaf, Editor 2013, The World Academic Publishing Co. Ltd.

[25] Toohid Bagherpoora LX. Structural Optimization Design of 2MW Composite wind turbine blade. Energy Procedia 2017;105:1226-33.

[26] Ullah H, Harland AR, Silberschmidt VV. Damage and fracture in carbon fabric reinforced composites under impact bending. Compos Struct 2013;101:144-56.

[27] Turon A, et al. An engineering solution for mesh size effects in the simulation of delamination using cohesive zone models. Eng Fract Mech 2007;74(10):1665-82.

[28] Ullah H, et al. Finite-element modelling of bending of CFRP laminates: Multiple delaminations. Comput Mater Sci 2012;52(1):147-56.

[29] Igwemezie V, Mehmanparast A, Kolios A. Materials selection for XL wind turbine support structures: A corrosion-fatigue perspective. Mar struct 2018;61:381-97.

[30] Khazar Hayat SKH. Load mitigation of wind turbine blade by aeroelastic tailoring via unbalanced laminates composites. Compos Struct 2015;128:122-33.

[31] Ullah H. Buckling of thin-walled cylindrical shells under axial compression. Int J Numer Meth Eng 2009;79:1332-53. 